\title{
ReaxFF MD Investigation of the High Temperature Combustion of Six Octane Isomers
}

Yang Liu ${ }^{a, b}$, Xin Wei ${ }^{a}$, Weizhen Sun ${ }^{a,}$, and Ling Zhao ${ }^{a, b}$

a State Key Laboratory of Chemical Engineering, School of Chemical Engineering, East China University of Science and Technology, Shanghai 200237, China

b School of Chemistry \& Chemical Engineering, XinJiang University, Urumqi 830046, China

\section{RESULTS AND DISCUSSION}

\subsection{Kinetic analysis of other octane isomers combustion}

The kinetic analysis of other octane isomers combustion was performed by employing the pseudo first order reaction assumption. The activation energy $\left(E_{a}\right)$ and pre-exponential factor $(A)$ are obtained by the linear fitting of $\operatorname{lnk}(\mathrm{T})$ and $1 / \mathrm{T}$ in Eq. (3-1). Figs. S1-S5 provide the relationships between $\operatorname{lnk}(\mathrm{T})$ and $1 / \mathrm{T}$ during the simulation process and Table S1 listed the detailed Arrhenius parameters $A$ and $E_{a}$ of the simulation。

$$
k=A^{*} \exp \left(-E_{a} / R T\right)
$$




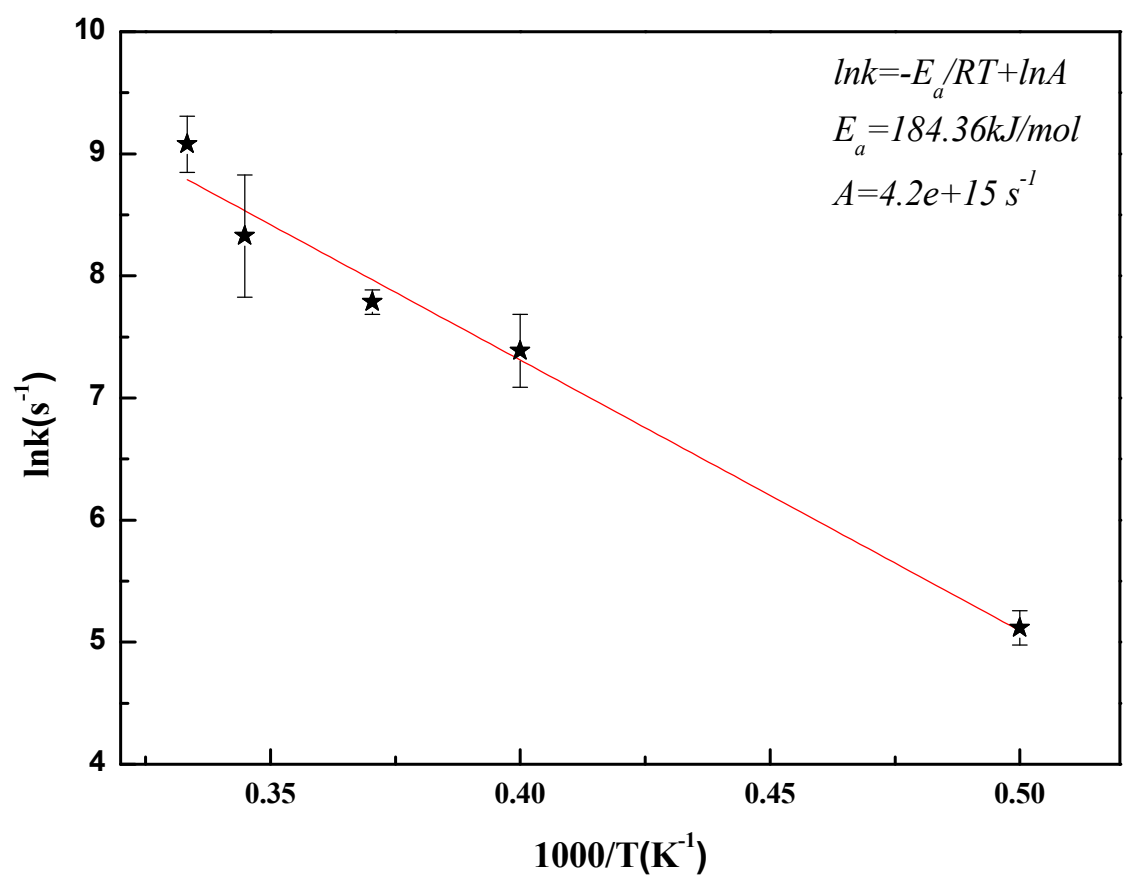

Figure S1. Correlation between $\operatorname{lnk}\left(\mathrm{s}^{-1}\right)$ and $1000 / \mathrm{T}\left(\mathrm{K}^{-1}\right)$ in n-octane system.

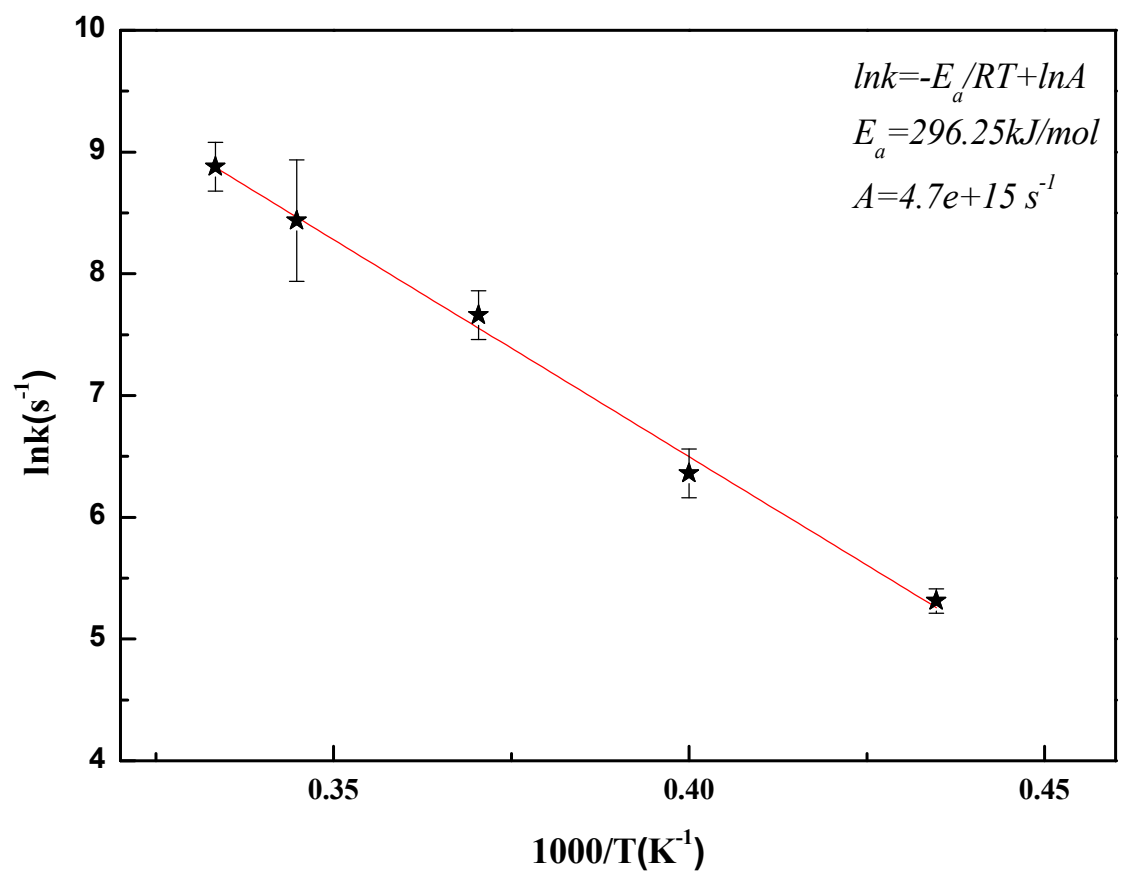

Figure S2. Correlation between lnk $\left(\mathrm{s}^{-1}\right)$ and $1000 / \mathrm{T}\left(\mathrm{K}^{-1}\right)$ in 3-methylheptane system. 


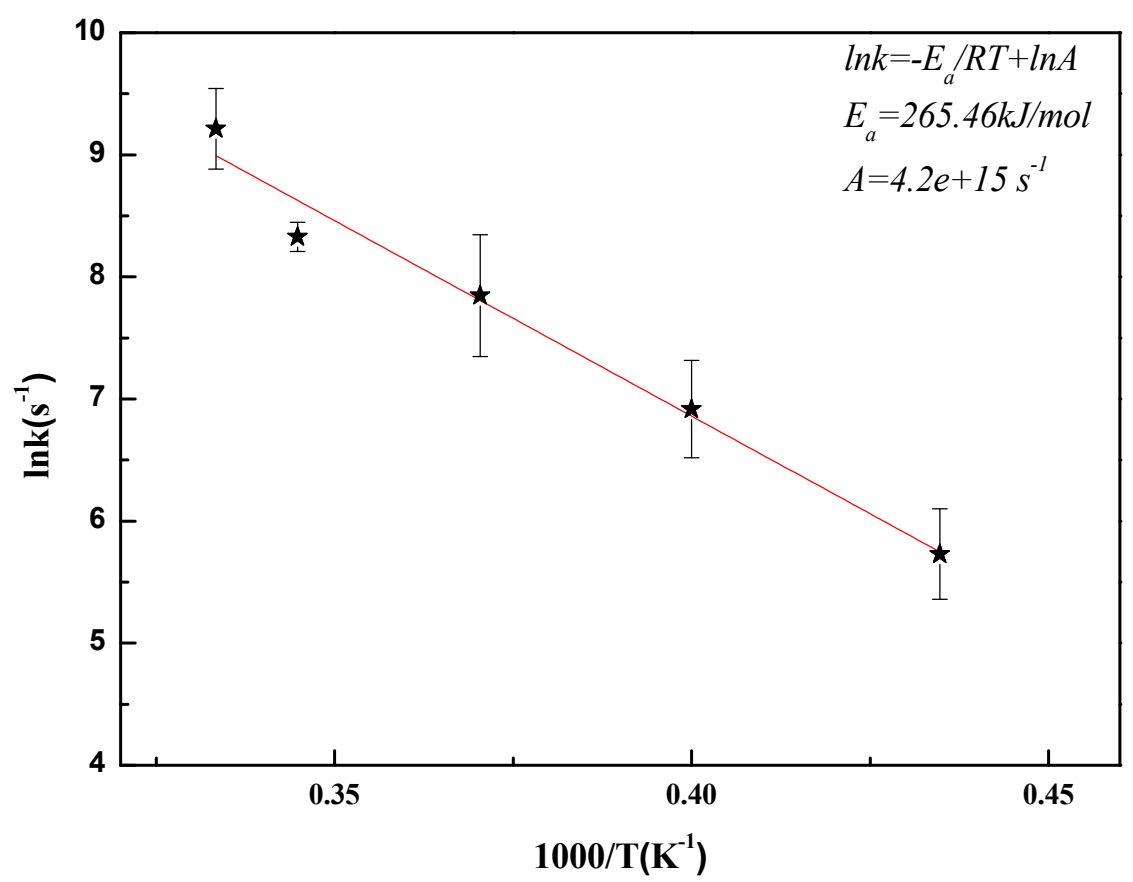

Figure S3. Correlation between $\operatorname{lnk}\left(\mathrm{s}^{-1}\right)$ and 1000/T $\left(\mathrm{K}^{-1}\right)$ in 2,5-dimethylhexane.

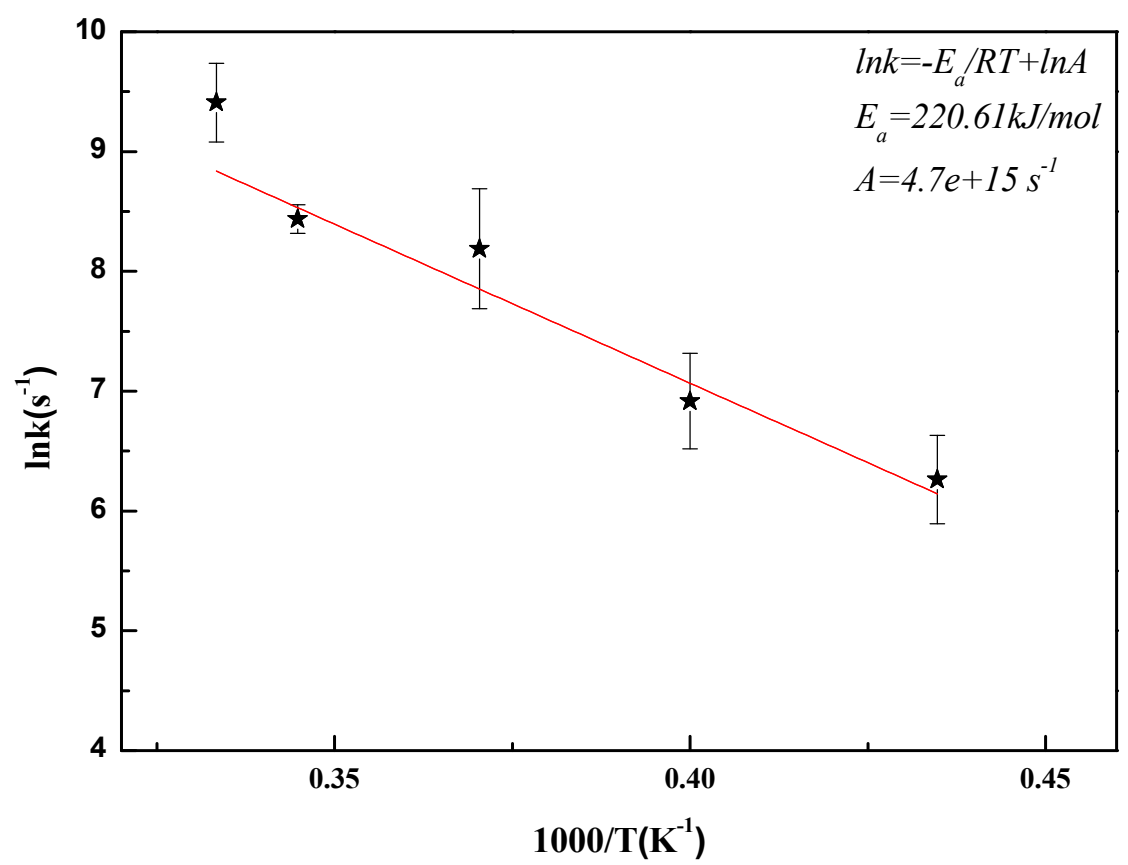

Figure S4. Correlation between $\operatorname{lnk}\left(\mathrm{s}^{-1}\right)$ and $1000 / \mathrm{T}\left(\mathrm{K}^{-1}\right)$ in 2.2.3.3-tetramethylbutane system. 


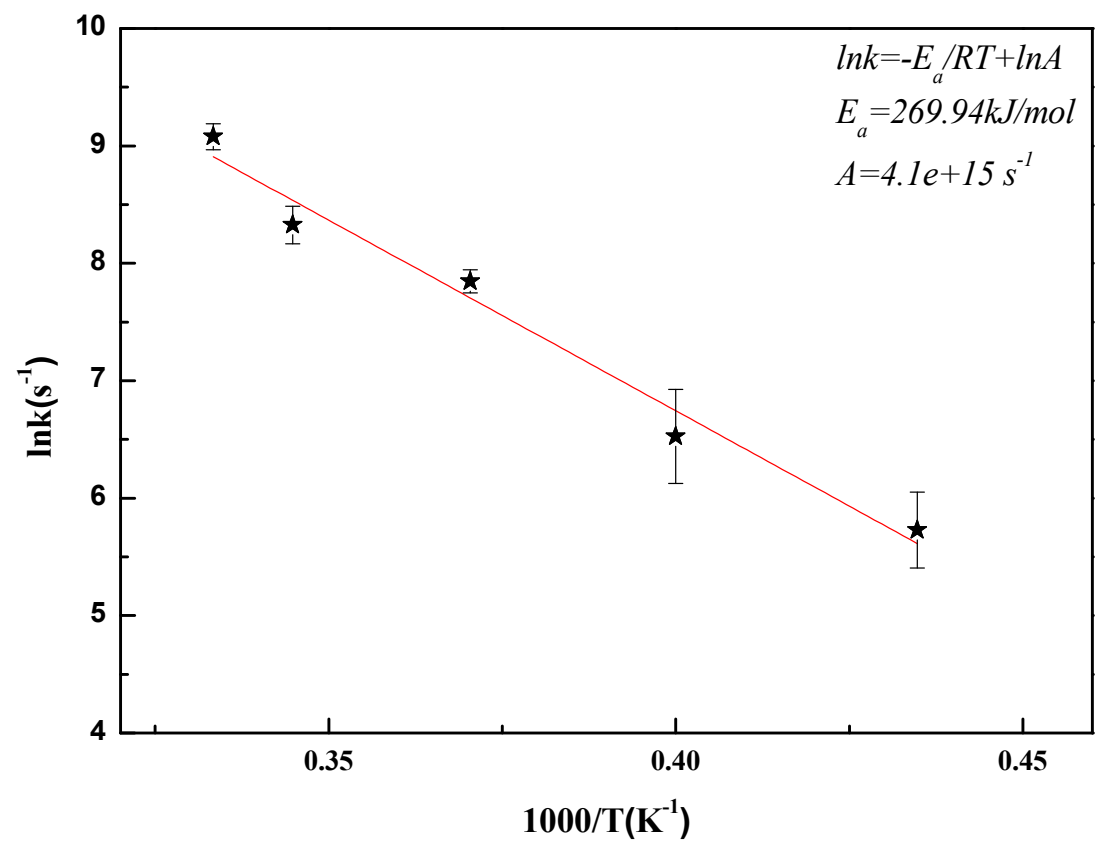

Figure S5. Arrhenius plot for the results of 3-ethylhexane.

\begin{tabular}{ccccc}
\hline & $A \mathrm{~s}^{-1}$ & $E_{a}(\mathrm{~kJ} / \mathrm{mol})$ & Temperature $(\mathrm{K})$ & $\mathrm{R}^{2}$ \\
\hline -octane & $1.01 \mathrm{e}^{*} 10^{16}$ & 186.36 & $2000-3000$ & 0.996 \\
3-methylheptane & $4.67 \mathrm{e}^{*} 10^{15}$ & 296.25 & $2000-3000$ & 0.998 \\
2,5-dimethylhexane & $4.12 \mathrm{e}^{*} 10^{15}$ & 265.46 & $2000-3000$ & 0.989 \\
& & & & \\
2,2,3,3-tetramethylbutane & $4.65 \mathrm{e}^{*} 10^{15}$ & 212.30 & $2000-3000$ & 0.959 \\
3-ethylhexane & $4.18 \mathrm{e}^{*} 10^{15}$ & 269.97 & $2000-3000$ & 0.989 \\
\hline
\end{tabular}

Table S1. The detailed Arrhenius parameters $A$ and $E_{a}$ in other octane isomer systems 